\title{
Estimating the impact of climate change on the occurrence of selected pests in the Central European region
}

\author{
E. Kocmánková1, ${ }^{1, *}$, M. Trnka ${ }^{1,2}$, J. Eitzinger ${ }^{3}$, H. Formayer ${ }^{3}$, M. Dubrovskýy ${ }^{1,2}$, \\ D. Semerádová ${ }^{1}$, Z. Žalud ${ }^{1}$, J. Juroch ${ }^{4}$, M. Možný ${ }^{5}$ \\ ${ }^{1}$ Institute for Agrosystems and Bioclimatology, Mendel University of Agriculture and Forestry in Brno, Zemědělská 1, \\ 61300 Brno, Czech Republic \\ ${ }^{2}$ Institute of Atmospheric Physics, Academy of Sciences of the Czech Republic, Boční II 1a, 14100 Prague 4, Czech Republic \\ ${ }^{3}$ Institute for Meteorology, University of Natural Resources and Applied Life Sciences (BOKU), Peter-Jordan-Str. 82, \\ 1190 Wien, Austria \\ ${ }^{4}$ State Phytosanitary Administration, Zemědělská 1a, 61300 Brno, Czech Republic \\ ${ }^{5}$ Czech Hydrometeorological Institute, Doksany Observatory, 41182 Doksany, Czech Republic
}

\begin{abstract}
The intensity and area of occurrence of pest species are strongly determined by the overall climate conditions of a locality and the weather pattern within a given season in combination with other factors (e.g. host plant abundance). While inter-seasonal weather variability and consequent fluctuations of individual pest species are well-known phenomena, changes in overall climate conditions and associated range shifts of particular species have likewise become important areas of research, especially during the last decade. The present study demonstrates the methodology and benefits of climate-driven modelling tools using the European corn borer (ECB) Ostrinia nubilalis (Hübner, 1796) and Colorado potato beetle (CPB) Leptinotarsa decemlineata (Say, 1824) as examples. CLIMEX models of the potential geographical distributions of each species were created and validated under present climate conditions. Both models were then used to study the effects of climate change on ECB and CPB by estimating changes in population dynamics and/or infestation pressure during the first half of the 21st century. Simulations were conducted using 3 global circulation models (HadCM3, NCAR-PCM, and ECHAM4) and scaled by low and high values of global temperature change. The results predict an increase in newly established areas and in the number of pest generations per year. The ratio of arable land affected by a particular number of generations is also expected to increase. Under the HadCM3-high 2050 scenario, this ratio increases by about 43 and $48 \%$ for the second generations of $\mathrm{CPB}$ and $\mathrm{ECB}$, respectively. Another significant result is shown for higher altitudes currently unoccupied by pests. We recorded rapid generation increase (from 0 to 2 ), which supports the hypothesis that these areas are more affected by increased temperatures.
\end{abstract}

KEY WORDS: Climate change $\cdot$ Pests $\cdot$ Geographical distribution $\cdot$ Altitude

\section{INTRODUCTION}

Pests and plant diseases are biotic factors that reduce crop yields, and their presence in agroecosystems can also affect yield quality parameters. Temperature is identified as the dominant abiotic factor directly affecting herbivorous insects (Bale et al. 2002). Climate can limit the distribution of a species directly by influenc- ing survival and fecundity, or indirectly through its effects on interacting species, including food sources, natural enemies, and competitors (Gaston 2003). Changes in climate conditions may therefore result in alterations in the geographical distribution of a species, variability in overwintering and population growth rates, increases in the number of generations, extension of the developmental period, effects on crop- 
pest synchrony, changes in interspecies interactions, and increased risk of invasion by migrant pests (Porter et al. 1991). An increase in the number of generations means an increase in the number of reproductive events per year. If the mortality per generation does not change, then populations of thermophilic insects may become larger under global warming (Yamamura \& Yokozawa 2002). This fact might play an important role in the case of multivoltine species (Pollard \& Yates 1993). Most of these species are expected to widen their areas of infestation to higher latitudes and altitudes, as has been reported for butterflies (Pollard et al. 1995, Hill et al. 1999, 2002, Parmesan et al. 1999). Increasing temperatures could support the earlier termination of diapause in overwintering species, causing them to appear earlier in the year. This would influence the intensity of crop-insect interactions (Yamamura \& Yokozawa 2002).

Under current climate conditions, insect species diversity per area tends to decrease with increasing latitude (Gaston \& Williams 1996, Wilf \& Labandeira 1999). A similar trend is usually seen with increasing altitude (Gaston \& Williams 1996). Warmer conditions may be expected to promote poleward extension of the ranges of species that are currently limited by low temperature. Alternatively, such species could shift in altitude to promote survival. An increase in temperature of $2^{\circ} \mathrm{C}$, which is expected to occur in northern temperate latitudes by the 2050s, is equivalent to a geographical shift under current conditions of about $600 \mathrm{~km}$ in latitude or $330 \mathrm{~m}$ in elevation. This shift is equivalent to approximately $6 \mathrm{~km}$ per year in latitude or $3.3 \mathrm{~m}$ per year in elevation (Bale et al. 2002).

The impacts of climate change on pest populations in the northern hemisphere will differ according to the current geographical positions of populations within each species' current range. In the northern hemisphere, populations occurring toward the northern margin of a species' range will be subject to greater climatic stresses than those occupying more central regions, and therefore are expected to be less stable. In other words, organisms near the limits of their ranges are typically most sensitive to change (Archer 1994).

The present study estimates the impact of climate change on 2 pest species: the Colorado potato beetle (CPB) Leptinotarsa decemlineata (Say, 1824) and the European corn borer (ECB) Ostrinia nubilalis (Hübner, 1796). The CPB is one of the most prevalent insect pests of potato crops around the world (Hare 1990) and is widespread in Europe (EPPO 2007). The occurrence of $\mathrm{ECB}$, which is the most prevalent insect pest of grain maize, has also been recorded across Europe by EPPO (2007). These 2 species are expected to broaden their range and to increase their infestation pressure due to climate change. The development of these species is closely related to climate conditions, especially to temperature patterns. The mechanisms by which climate conditions affect development can be analysed using the CLIMEX software tool. CLIMEX has recently been applied in various scientific studies considering the potential distribution and spread of animal and plant species (e.g. Sutherst 2000a,b, Bell \& Willoughby 2003, Kriticos et al. 2003, Lockett \& Palmer 2003, Pethybridge \& Wilson 2003, Rafoss \& Saethre 2003, Zalucki \& Furlong 2005, Olfert \& Weiss 2006).

In the present study, CLIMEX is used to estimate climate limits for population growth of both pest species in the Czech Republic and northern Austria (in the federal states of Lower and Upper Austria and Burgenland) based on their current geographical distributions. Under present climate conditions in the Czech Republic, ECB usually develops 1 generation per year, producing 2 generations only in very warm growing seasons. The occurrence of a second generation of ECB in central Europe is limited by photoperiod as well as temperature (Trnka et al. 2007). CPB develops 1 or 2 generations per year in the Czech Republic and Austria. The largest economic losses caused by this pest occur in warmer lowland areas in the southeastern and northwestern Czech Republic and in the Marchfeld lowland region of northeastern Austria. Due to the favourable climate conditions in these regions, the pest species can produce 2 generations per year. Occurrence data obtained from field observations in the Czech Republic constitute the basis for validation of the range models under recent climate conditions. Following validation and calibration of the model output, the input meteorological data were altered based on 3 global circulation models (ECHAM4, HadCM3, and NCAR-PCM) driven by 2 emission scenarios - A2 and B1 - from the IPCC SRES (special report on emissions scenarios with 2 assumed levels of climate system sensitivity 2020-2050. Model outputs for current and expected climate conditions were visualised using geographical information systems using a digital landscape model.

\section{MATERIALS AND METHODS}

The climate-matching software program CLIMEX estimates the geographical distribution of a species based on the climate conditions of a given location. CLIMEX is based on the assumption that if you know where a species lives you can infer what climatic conditions it can tolerate. In other words, CLIMEX attempts to mimic the mechanisms that limit species' geographical distributions and determine their seasonality. CLIMEX is a climate- rather than a weather-driven modelling program that is designed to provide insights into species' requirements for climate, as expressed by their geo- 
graphical distribution, seasonal phenology, and relative abundance. CLIMEX is based on the premise that it is possible to define climates that are conducive to the generation of particular weather patterns, which directly affect populations on a short time-scale (Sutherst et al. 2000). The software has been used extensively in the fields of biological control, climate change, and pest risk assessment, with positive results in many countries. The CLIMEX model is designed to extract maximum information out of minimal field data on the response of a species to climate. It derives weekly and annual indices that describe the responses of a nominated species to temperature and moisture, and, in the case of plants, light (Sutherst 2003).

These properties make CLIMEX an appropriate tool for planning questions about issues such as risk assessment in integrated pest management as well as quarantine, biological control, or climate variability and long-term climate change (Sutherst et al. 2000). Knowing the climatological requirements of a given species allows us to assess the suitability of a particular area for population growth and to determine the stress induced by unsuitable climate conditions. These are expressed in terms of the ecoclimatic index (EI), which describes the overall suitability of climate conditions for the establishment and long-term presence of a pest population at a given location:

$$
\mathrm{EI}=\mathrm{GI}_{\mathrm{A}} \times \mathrm{SI} \times \mathrm{SX}
$$

where $\mathrm{GI}_{\mathrm{A}}$ is the annual growth index describing population growth under favourable conditions, SI is the annual stress index describing survival during unfavourable periods, and SX represents stress interactions. The calculation of $\mathrm{GI}_{\mathrm{A}}$ and stress indices is based on the ranges of threshold parameters for species development adjusted by the user (Table 1). Temperature parameters include the lower and upper thresholds and optimal range of air temperature for development, and similar parameters are used for soil moisture. In the present study, soil moisture thresholds were set to values representing the optimal moisture conditions for the pest species' development. In the model validation procedure, we found that this approach was most appropriate because it prevented the incorrect estimation of high dry/wet stress, which would cause an undesirable decrease in EI.
In addition to temperature and moisture limitations, CLIMEX also takes into account the process of diapause, which is driven by temperature (initiation and termination temperature) and day-length thresholds. The number of generations is calculated based on the number of degree-days above the lower temperature threshold per generation.

Generally EI ranges from 0 to 100, where EI $=0$ indicates climate conditions unfavourable for long-term species occurrence and EI $>30$ represents very suitable climate conditions for species occurrence (Sutherst \& Maywald 1985, Sutherst et al. 2001). Hoddle (2004) considers locations with EI $>25$ as very favourable for species occurrence, $10<\mathrm{EI}<25$ as favourable, and EI $<10$ as limiting for species survival and occurrence. CLIMEX models use input data on a monthly scale (minimum and maximum temperature, relative humidity at 09:00 and 15:00 $\mathrm{h}$, and precipitation), which are readily available.

The input weather series were prepared by a weather generator (Dubrovský et al. 2000, 2004) for the period from 1961 to 1990. Model validation was carried out by comparing the modelled range of a particular pest to the current area of occurrence obtained from field observations for the period from 1961 to 1990. In the present study, the CLIMEX models were first validated using observed occurrence data for ECB and $\mathrm{CPB}$ in the Czech Republic. To generate weather series representing climate conditions in 2020 and 2050, the parameters of the weather generator were modified according to the 3 climate change scenarios (HadCM3, NCAR-PCM, and ECHAM4) (Dubrovský et al. 2005). Temperature and precipitation change based on specific scenarios measured in terms of months and years is depicted in Fig. 1. Our choice of the 3 General Circulation Models (GCMs) was based partly on validation tests (Dubrovský et al. 2005) in which the authors found the best GCMs for simulating the present climate in the Czech Republic, and partly on the fact that these models belong to the most frequently used GCMs in climate change impact studies, which will allow comparison of our results with other studies.

The output of the model was first calculated for 111 weather stations in the Czech Republic and 17 weather stations in northern Austria. Then the results were interpolated over the whole area. The potential geo-

Table 1. Parameters of the CLIMEX model for the development of Colorado potato beetle (CPB) and European corn borer (ECB)

\begin{tabular}{|lccccccc|}
\hline $\begin{array}{l}\text { Development } \\
\text { threshold }\end{array}$ & $\begin{array}{c}\text { Lower temp. } \\
\text { threshold } \\
\left({ }^{\circ} \mathrm{C}\right)\end{array}$ & $\begin{array}{c}\text { Optimum } \\
\text { temp. range } \\
\left({ }^{\circ} \mathrm{C}\right)\end{array}$ & $\begin{array}{c}\text { Higher temp. } \\
\text { threshold } \\
\left({ }^{\circ} \mathrm{C}\right)\end{array}$ & $\begin{array}{c}\text { Diapause } \\
\text { induction } \\
\text { temp. }\left({ }^{\circ} \mathrm{C}\right)\end{array}$ & $\begin{array}{c}\text { Diapause } \\
\text { induction } \\
\text { daylength }(\mathrm{h})\end{array}$ & $\begin{array}{c}\text { Diapause } \\
\text { termination } \\
\text { temp. }\left({ }^{\circ} \mathrm{C}\right)\end{array}$ & $\begin{array}{c}\text { Degree-days } \\
\text { per } \\
\text { generation }\end{array}$ \\
\hline $\mathrm{CPB}$ & 12 & $15-28$ & 33 & 13 & 10 & 13.5 & 400 \\
$\mathrm{ECB}$ & 10 & $18-28$ & 38 & 12 & 10 & 726 \\
\hline
\end{tabular}



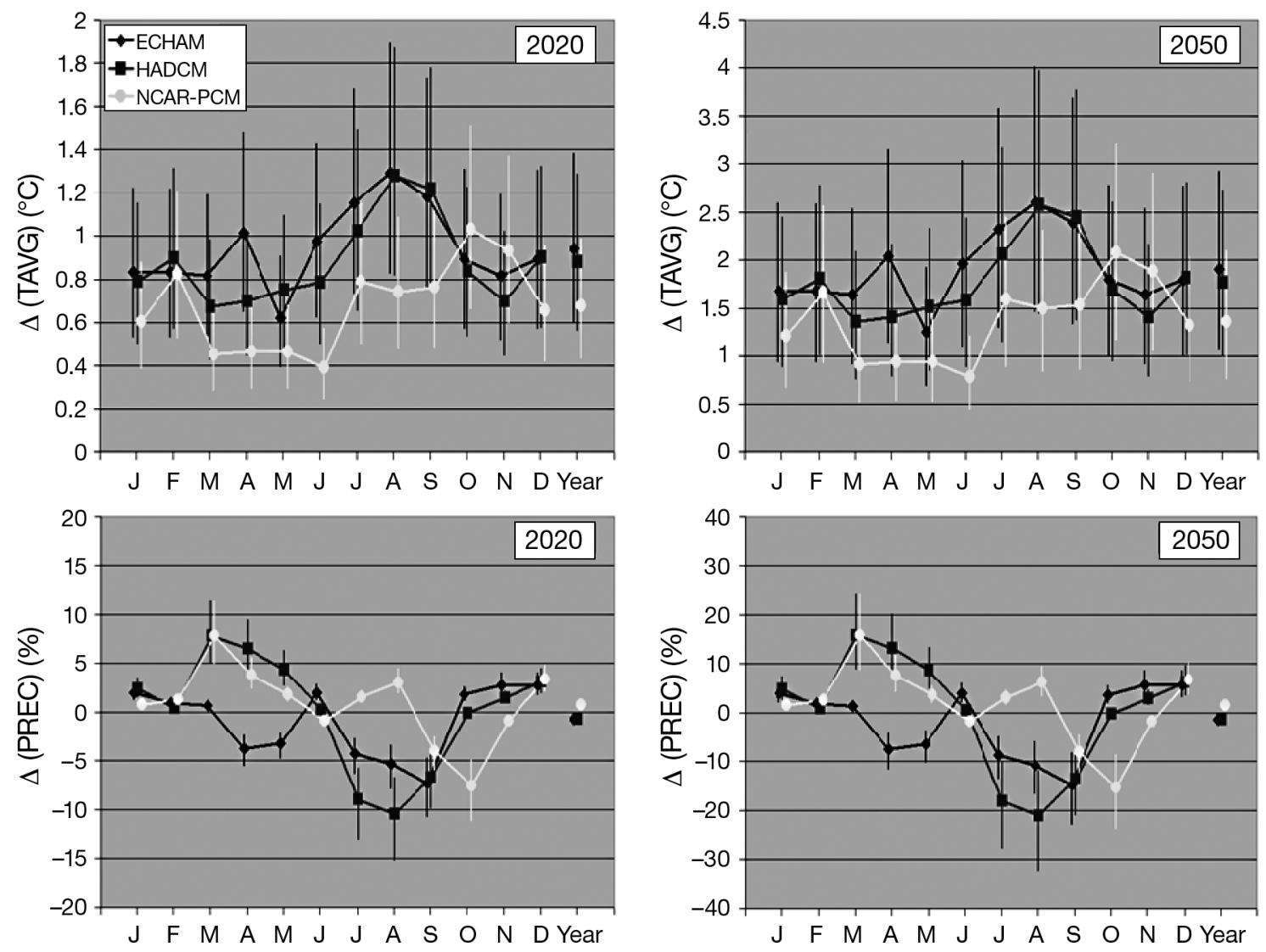

Fig. 1 Change of mean monthly and yearly temperature and precipitation based on selected scenarios (ECHAM, HadCM3, NCAR-PCM) in 2020 and 2050 in the Czech Republic. Curves represent the mean estimation; vertical lines depict the range of values corresponding to emission scenario SRES-B1 low (lower layer) and SRES-A2 (upper layer)

graphical distributions of each pest species under both current and expected climate conditions were visualised as maps interpolated to $1 \mathrm{~km}$ resolution using a digital terrain model.

\section{RESULTS}

\subsection{European corn borer Ostrinia nubilalis}

Current climate conditions in the Czech Republic permit the development of one generation of ECB per year in lowland areas of central Bohemia and southern Moravia. The area where a complete first generation occurs is depicted in Fig. 2 ( $E I=21$ to 24.9). The area occupied by the first generation of ECB in the Czech Republic agrees closely with the observed area of occurrence from 1961-1990, as shown in Kocmánková et al. (2008a). The first generation is established in the lowlands, especially in Lower Austria (Marchfeld region), and the EI values of 25 to 31.9 at the lowest altitudes of Burgenland and Lower Austria indicate a partial second generation of the pest.
Fig. 3 demonstrates the change in the number of generations under the 3 climate scenarios (ECHAM4, HadCM3, and NCAR-PCM) combined with A2-high climate sensitivity in 2020 and 2050. Based on the results, increasing temperature clearly leads to widening of the area occupied by the first generation of the pest; this pattern occurs under all scenarios in both 2020 and 2050. Areas where the number of generations is expected to increase from 0 to 1 are marked with a light grey colour in Fig. 3. In these areas, climate conditions will shift from conditions that do not allow the establishment of pest populations to conditions that permit the persistence of viable populations. Therefore, the pest is likely to colonise recently unoccupied areas by shifting the first generation to higher altitudes in relation to the current climate (cross-hatched area). The widening of the area occupied by one generation is modest in the HadCM3-high for 2020 (Fig. 3b), while in the maps for 2050 (Fig. 3e), one generation covers almost all of the Czech Republic except at altitudes above $800 \mathrm{~m}$ above sea level (a.s.l.).

In the majority of areas where one generation currently occurs in south Moravia and the Austrian low- 


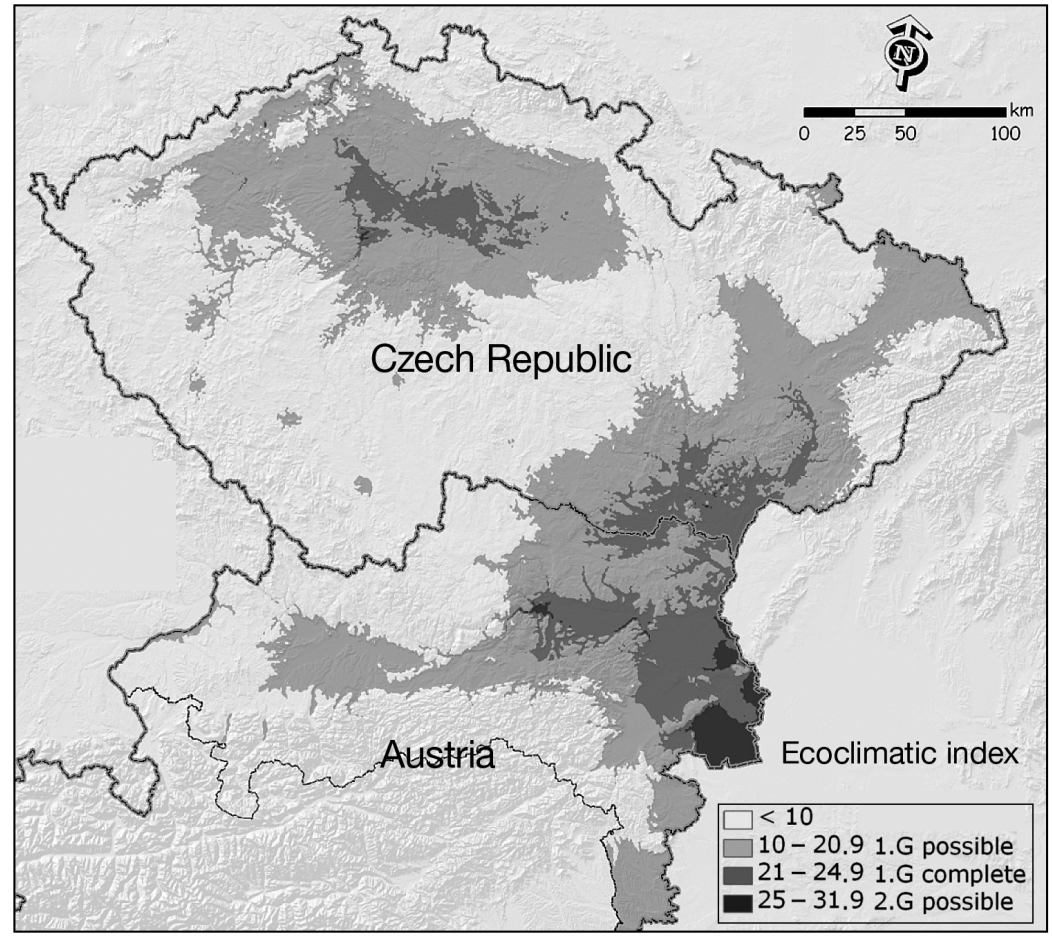

lands, the number of generations may increase from 1 to 2 by 2020, according to scenario HadCM3-high (dark grey colour in Fig. 3, map b). The greatest impact of increased temperatures in 2020 is found under scenario HadCM3-high in areas where the pest is not currently established but develops 2 generations under the expected climate scenario. This occurs around the border and small lowland areas in southern Moravia and Lower Austria (black colour).

As mentioned, the first generation is expected to occupy areas up to $800 \mathrm{~m}$ a.s.l. in 2050. In all scenarios for 2050,

Fig. 2 Ostrinia nubilalis. Potential geographical distribution of the European corn borer (ECB) under present climate conditions based on climate data from 1961 to 1990 . G: generation. Thin black line: southern limit of study area
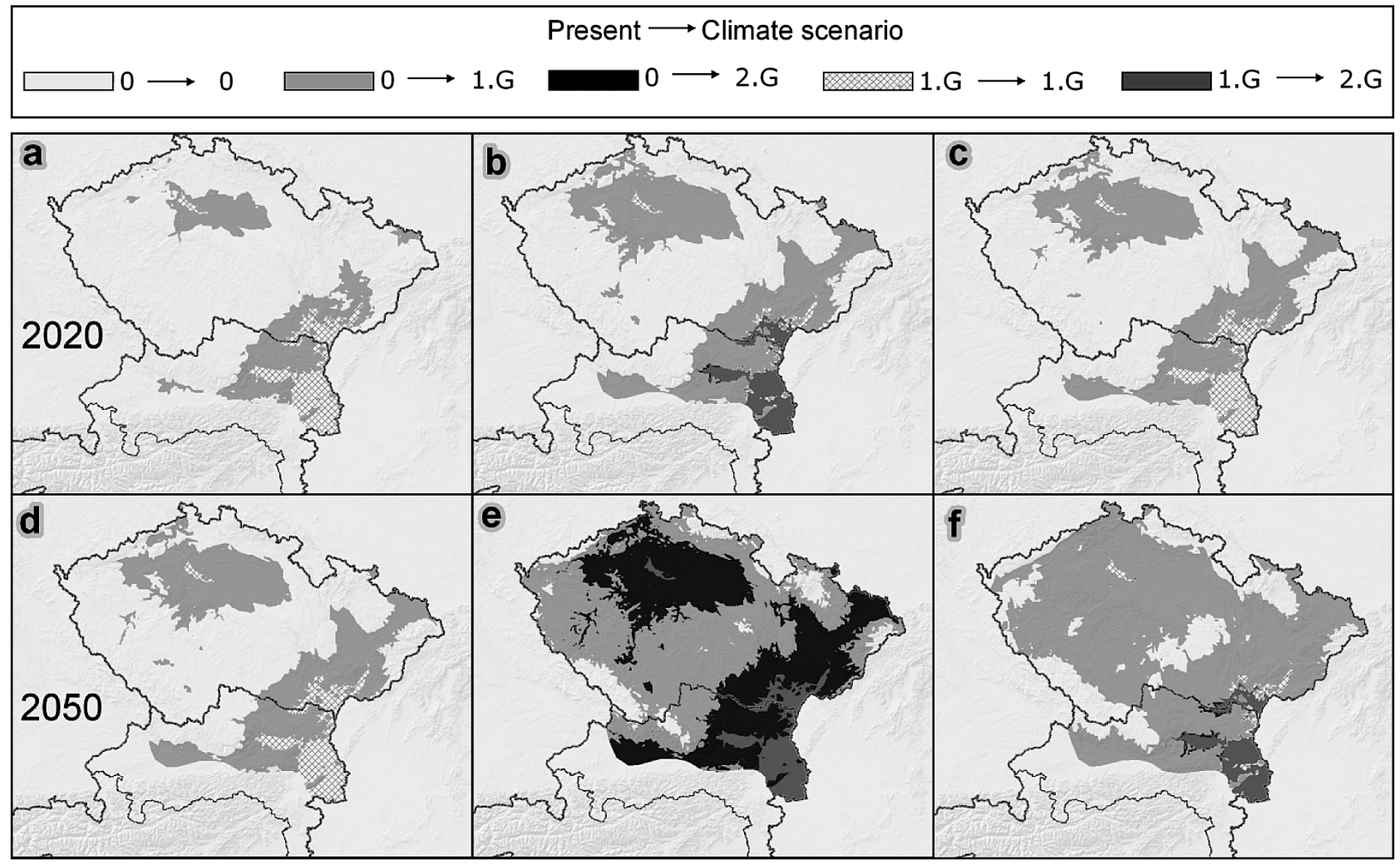

Fig. 3 Ostrinia nubilalis. Increase in the number of generations of the European corn borer (in terms of Ecoclimatic index) under expected climate conditions based on meteorological data simulated under scenarios ECHAM4 (a,d), HADCM3 (b,e) and NCARPCM (c,f) combined with emission scenario A2 in 2020 and 2050. Lightest grey shade: no occurrence of the pest due to an incomplete first generation; cross-hatched areas: no change compared to the current climate; other grey shades: increase in the number of generations. G: generation 
areas where one generation currently occurs are mostly expected to support 2 generations. Complete substitution of 2 generations for one is seen in scenario HadCM3-high (map e). Simultaneously, the second generation also covers surrounding areas at higher altitudes where the increase in temperature is large. This is evident when comparing generation numbers under the current climate versus the expected climate under scenario HadCM3-high for 2050, which shows a relative imbalance in the increase in generation number (Fig. 3, map e). The increase in generation number is markedly greater at higher altitudes than in lower areas. This is represented by the area where generation number increases from 0 to 2 (shown on map as black), which appears at higher elevations where the number of degree-days does not allow the completion of one generation under the current climate, but the temperature increase under the expected climate fulfils the conditions required to develop 2 generations. This result sup-

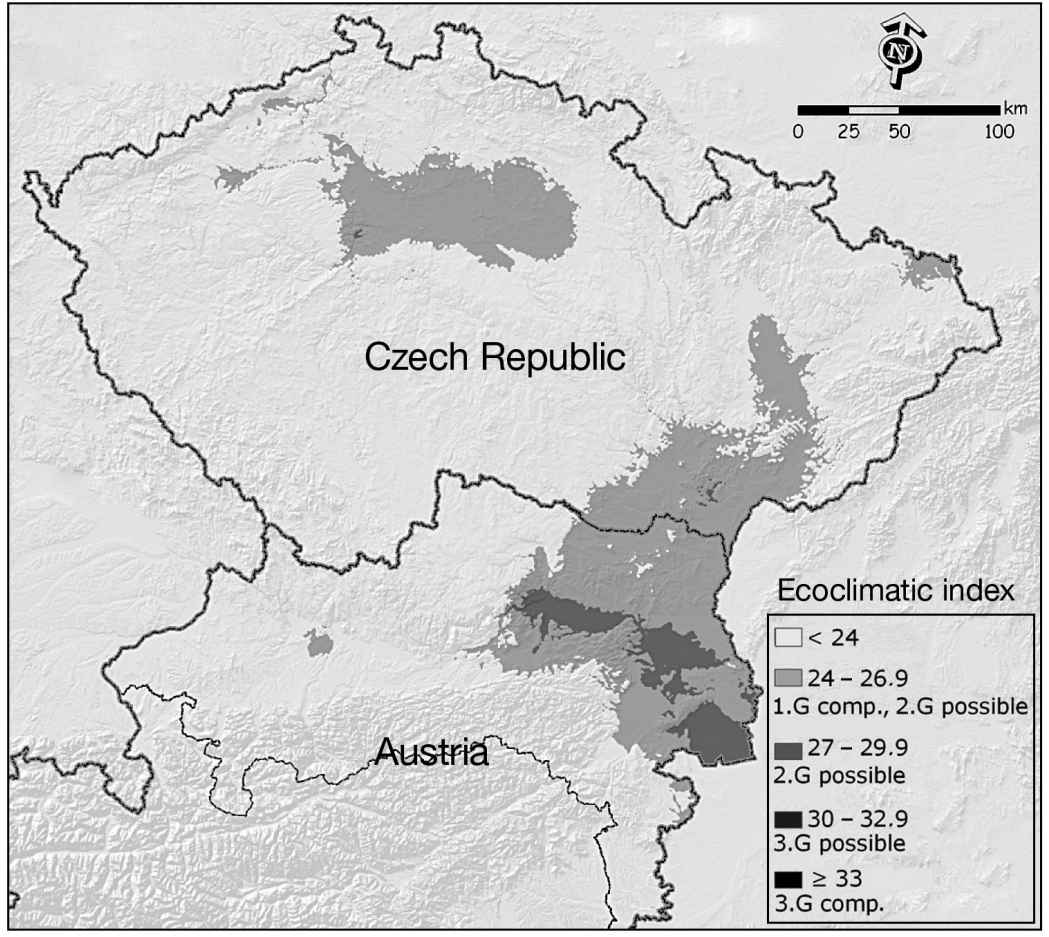

Fig. 4 Leptinotarsa decemlineata. Potential geographical distribution of the Colorado potato beetle $(\mathrm{CPB})$ under present climate conditions based on climate data from 1961 to 1990. comp.: complete; G: generation ports the hypothesis that climate change will lead to more dramatic shifts at higher altitudes and that higher altitudes are likely to be more affected by increased temperatures and therefore are more vulnerable.

\subsection{Colorado potato beetle Leptinotarsa decemlineata (Say, 1824)}

Currently, one generation of CPB occurs in the Czech Republic, but lowland areas can be occupied by 2 generations during particularly warm seasons. Climate conditions from 1961-1990 (Fig. 4) allow the development of a partial second generation of the pest in lowland areas of the Czech Republic, corresponding to the observed area of occurrence, as shown by Kocmánková et al. (2008b). The area of establishment of a partial second generation is indicated by light grey colour ( $E I=24-26.9)$. In Austria, climate conditions are suitable for the development of a partial second generation in the lowlands of Lower Austria and Burgenland, with a full second generation occurring at the lowest altitudes (grey colour, EI = 27-29.9).

Based on the climate conditions expected under the selected scenarios, increasing temperatures result in an increased number of generations, as shown in Fig. 5. A2-high scenarios for 2020 (ECHAM4, HadCM3

and NCAR-PCM; a, b, and c, respectively) show widening of the area covered by one generation (shown on the map as hatched). Areas originally occupied by one generation support a second generation (HadCM3-high and NCAR-PCM-high for 2020; midgrey).

The significant increase in number of generations is also seen in scenarios for 2050. Except for the occurrence of a second generation in the area that originally supported one generation, scenarios for 2050 show more rapid increases in generation number. In the lowlands of middle Bohemia, Moravia, and Austria, the number of generations increases from 1 to 3 (HadCM3high for 2050, map e; shown on map as dark dotted areas). Another significant change is shown by the scenarios HadCM3-high and NCAR-PCM-high for 2050, which indicate the emergence of a second generation in currently unoccupied areas at higher altitudes (HadCM3-high, map e, NCAR-PCM-high, map $f_{i}$ shown on map as black). This rapid generation increase (from 0 to 2 generations) at higher elevations is similar to the increase in ECB generation number relative to altitude (see Section 3.1). The areas shown on the map as cross-hatched in the lowland areas of Lower Austria and Burgenland in Fig. 5 marks the unchanged occurrence of 2 generations. 

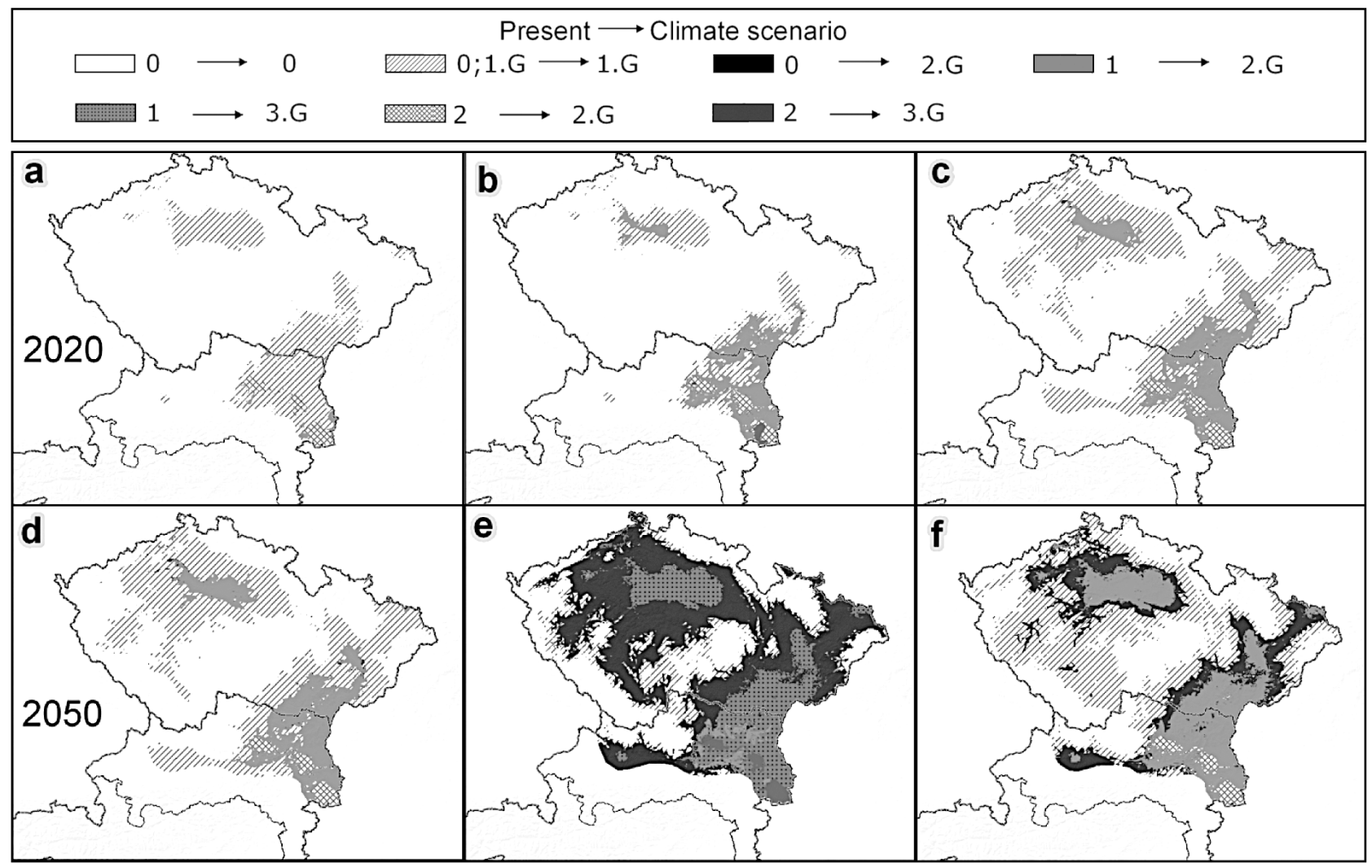

Fig. 5. Leptinotarsa decemlineata. Increase in the number of generations of the Colorado potato beetle (in terms of Ecoclimatic index) under expected climate conditions based on meteorological data simulated under scenarios ECHAM4 (a,d), HADCM3 (b,e) and NCAR-PCM $(\mathrm{c}, \mathrm{f})$ combined with emission scenario A2 for 2020 and 2050. Lightest grey: no occurrence of the pest due to an incomplete first generation; hatched: increase from zero to one generation compared to the current climate, or no change (continual presence of one generation); other grey shades: increase in the number of generations

\section{DISCUSSION}

Our results demonstrate that expected increases in temperature will most likely shift the developmental limitations of pest species and permit widening of their areas of occurrence and shifts to higher altitudes. Under these scenarios, both pest species could complete their development earlier in the year and produce more generations. As they relate to agricultural production, simulations of baseline climate conditions in the Czech Republic and Austria indicate that $9.8 \%$ of arable land is threatened by the occurrence of one generation of ECB (Table 2). Under future climate conditions, there is a significant increase in the percentage of arable land where protective measures are needed due to the occurrence of one pest generation. For HadCM3-low in 2050 , this percentage increases by about $48.8 \%$, and for NCAR-PCM-high in 2050 the increase is $82.3 \%$. Protective measures connected with the presence of a second generation will likely be needed for $58.1 \%$ of arable land in Austria and the Czech Republic, according to the scenario HadCM3-high for 2050.
Under the current climate, $27.7 \%$ of arable land in the Czech Republic and Austria is affected by one generation of CPB (Table 2). Under expected climate conditions, the area requiring protection against one generation of CPB increases by about $13.5 \%$ (ECHAM4low for 2050), while protection against a second generation will likely be necessary for $48.6 \%$ more arable land (NCAR-PCM-high for 2050). Under the scenario HadCM3-high for 2050, a third generation is expected to occur in $33.6 \%$ of the total arable land. The largest changes are expected at higher altitudes currently unoccupied by the pests. This is because in higher altitude regions with cooler conditions, the pests are already close to their limit to complete the first generation.

However, additional factors involved in pest occurrence must be taken into consideration. Shreeve et al. (1996) point out that the area near the extreme border (in latitude) of a species' range is marginal in the sense that environmental factors influencing the probability of population survival and persistence are more intense than in regions to the south, where species are less restricted and occur across a wider range of habi- 
Table 2. Percentage of arable land occupied by a particular number of generations of the Colorado potato beetle (CPB) and European corn borer (ECB) under current and expected climate conditions based on HadCM3, NCAR-PCM, and ECHAM4 high and low scenarios scenarios in 2020 and 2050. Climate conditions estimated by particular scenarios do not assume the presence of a 3rd generation of ECB

\begin{tabular}{|c|c|c|c|c|c|c|c|c|c|c|c|c|c|}
\hline & \multirow[t]{3}{*}{$1961-1990$} & \multicolumn{4}{|c|}{$\longrightarrow$ ECHAM } & \multicolumn{4}{|c|}{- HadCM3 } & \multicolumn{4}{|c|}{ NCAR } \\
\hline & & \multicolumn{2}{|c|}{2020} & \multicolumn{2}{|c|}{2050} & \multicolumn{2}{|c|}{2020} & \multicolumn{2}{|c|}{2050} & \multicolumn{2}{|c|}{2020} & \multicolumn{2}{|c|}{2050} \\
\hline & & Low & High & Low & High & Low & High & Low & High & Low & High & Low & High \\
\hline \multicolumn{14}{|c|}{ 1st generation } \\
\hline $\mathrm{CPB}$ & 27.7 & 35.2 & 7.6 & 40.8 & 39.2 & 36.1 & 6.7 & 36.8 & 11.7 & 32.1 & 40.3 & 38.4 & 33.5 \\
\hline $\mathrm{ECB}$ & 9.8 & 31.0 & 33.0 & 43.7 & 54.7 & 39.3 & 47.8 & 58.6 & 41.3 & 25.1 & 52.8 & 40.3 & 92.1 \\
\hline \multicolumn{14}{|c|}{ 2nd generation } \\
\hline $\mathrm{CPB}$ & 1.6 & 9.1 & 1.7 & 13.4 & 23.4 & 13.5 & 15.4 & 30.6 & 44.2 & 5.9 & 20.6 & 12.5 & 50.2 \\
\hline ECB & 0 & 0 & 0 & 0 & 0 & 0 & 7.8 & 0 & 58.1 & 0 & 0 & 0 & 0 \\
\hline \multicolumn{14}{|c|}{ 3rd generation } \\
\hline $\mathrm{CPB}$ & 0 & 0 & 0 & 0 & 0 & 0 & 0 & 0 & 33.6 & 0 & 0 & 0 & 0 \\
\hline ECB & & & & & & & & & & & & & \\
\hline
\end{tabular}

tats. An increase in temperatures would decrease marginality, resulting in coalescence of previously isolated populations and increased stability. If such a scenario also applies to moth pests with similar Palaearctic distributions, then an increase in pest pressure is very likely. For multivoltine species such as Ostrinia nubilalis, which are already distributed over a very wide latitudinal range in Europe, successful colonisation of northwardly expanded maize crops will depend on factors such as migration ability and the rate at which climate changes occur (Cannon 1998).

Tobin et al. (2008) have applied a phenological degree-day model for a temperate moth species Paralobesia viteana. Based on their study, the number of generations of multivoltine insect species is likely to increase, and such increases can greatly exacerbate the negative ecological and economical costs of insect pest species. Tobin et al. (2008) illustrated that increases in mean surface temperatures of $>2^{\circ} \mathrm{C}$ can have dramatic effects on insect voltinism by causing a shift in the ovipositional period, which is currently subject to diapause-inducing photoperiods. Tran et al. (2007) have suggested that cold-limited species may be able to increase their geographic ranges in the future - in the forests of the eastern United States, several beetles (e.g. southern pine beetle Dendroctonus frontalis) are expected to expand their ranges northward.

According to one of the first studies on the impact of climate change on ECB populations in Europe (Porter et al. 1991), a temperature increase associated with ongoing climate change would lead to a northward shift of the area affected by ECB and possibly to the occurrence of a second generation in presently univoltine areas. The results of the present study are also supported by estimates based on the more detailed ECAMON model (Trnka et al. 2007). However, comparing the potential occurrence of ECB as assessed by both the ECAMON and CLIMEX models (Kocmánková et al. 2008a) shows that CLIMEX tends to underestimate the potential geographical distribution compared to ECAMON, which seems to be a more sensitive tool for estimating the occurrence of ECB as indicated by a better fit to the observed data. This superiority of ECAMON over CLIMEX is explained by a very detailed developmental module and the use of daily time steps compared to the crude climatology used in CLIMEX. Detailed evaluation of the model has proven ECAMON's capability to accurately estimate the initiation and persistence of crucial phenological stages. On the other hand, the main advantage of CLIMEX is that it has far lower input data requirements and yet yields relatively reliable results. In the case of an expected increase in temperature and seasonal shift (Dubrovský et al. 2005), both models estimate expansion of ECB into higher altitudes under the selected SRES scenarios. One of the primary conclusions of both models is that climate is a significant factor determining the development and survival of ECB. However, the CLIMEX results shown in the present study could also be seen as minimal estimates of the potential future risk of this pest.

The simulated geographical distribution represents the potential occurrence of pest infestations or the area with climatic conditions suitable for the occurrence of viable populations of $\mathrm{ECB}$, which is usually associated with economically significant densities. The study did not take host presence into account because of the wide range of possible host species for ECB. This is not thought to be a severely limiting factor, although it may significantly slow developmental rates (Anderson et al. 1982). It is important to emphasize that the CLIMEX model defines the potential geographical distribution of a given biological organism in relation to climate (Sutherst 2003). Sutherst \& Maywald (1985) 
stated a caveat that users of CLIMEX need to exclude non-climatic factors limiting the distribution before assuming that climate is the only factor. The CLIMEX model defines the role of climate as a factor in determining the potential for establishment when all other factors are not included (Sutherst 2003). The second caveat relates to any assumption that climate alone limits the geographical distribution, because biological or other physical factors reduce the population growth and so may prevent the species from occupying the whole area that is climatically suitable for it, referred to as the fundamental niche (Hutchinson 1957). This conception of the CLIMEX model assumes that the main source of the assessment uncertainty is contained in the climate portion of the model. Measure of the given uncertainty is subjected to the selected GCMs with their different annual cycles of seasonal changes in temperature and precipitation.

Baker et al. (2000) have adopted the CLIMEX approach to study the effect of climate change on the potential distribution of CPB. Their study confirms the widening of the area of occurrence of CPB under climate change conditions expected by the CLIMEX simulation of climate suitability in the UK and Europe. The greatest increases in suitability for CPB according to the Baker et al. (2000) study lie between 50 and $65^{\circ} \mathrm{N}$ latitude in northern Europe. Further simulations of the occurrence of CPB as an exotic pest in Norway (Raffos \& Sæthre 2003) indicate that the current climate is not suitable for long-term establishment of this species. The climate change scenarios clearly indicate that a temperature increase could shift the conditions from nonfavourable to favourable for CPB in several regions. Jarvis \& Baker (2001) have used an insect development model for CPB coupled with daily temperature data to explore the likelihood of this pest becoming established in England and Wales. This sophisticated model uses a daily time step, permitting the use of indices including estimates of pest activity and flight potential.

There is an apparent risk of increasing damage caused by pests due to shifting climate conditions. It should be stressed that the present study is based on so-called potential distribution, which means that the expected geographical distribution of a given species is based only on climate conditions regardless of other factors that may determine the species' abundance or distribution. Other factors could be included, but that would require extensive modification of the CLIMEX model, e.g. by integrating growth models for host plants, estimating the occurrence of drought periods under the future climate scenario, and implementing feedback from new management strategies and crop varieties. Despite the simplifications, the present study offers valuable data that should be considered for activities dealing with adaptation to climate change.
Araujo \& Luoto (2007) refer to growing evidence for evolutionary shifts in insects exposed to climate change. When predicting direct effects of climate change, phenotypic and genotypic flexibility of herbivores and interactions between species must be considered. Levels of heritable variation for traits likely to be involved in adaptation to climate change have been investigated in several herbivores. Examples include recent work on variation in the timing of egg hatch in winter moths to counter an increasing mismatch between the herbivore and its host (van Asche et al. 2007) and variation in thermal responses of the CPB (Lyytinen et al. 2008). According to Thomson et al. (2009), thermal thresholds might be plastic as a consequence of acclimation, but there is no allowance for the possibility that thresholds might evolve because of selection imposed by climate change.

Climate change is expected to affect agriculture very differently in different parts of the world (Parry et al. 2004). It may have important consequences for agricultural land use and sustainable use of agricultural soil water resources in this continental climate region (Downing et al. 2000). According to Olesen (2008), changes in climate patterns are expected to greatly affect all components of the European agricultural ecosystems (e.g. crop suitability, yield and production, livestock, etc.). In northern areas, climate change may produce positive effects on agriculture through introduction of new crop species and varieties, higher crop production, and expansion of suitable areas for crop cultivation. Disadvantages may be an increase in the need for plant protection. In southern areas the disadvantages will predominate. The possible increase in water shortage and extreme weather events may cause lower harvestable yields, higher yield variability, and a reduction in suitable areas for traditional crops.

The method presented here plays an important role in estimating species' occurrence depending on their climate requirements, but the method is limited by its lack of field- or population-level interactions. Climatic mapping may therefore be a very useful tool in pest risk analyses under changing climate because it allows us to estimate the risk of introduction, colonisation, and spread of various pest species and their economic impacts. However, the present study also demonstrates, using 2 pest species as examples, that any long-term pest risk analysis must take climate change into account because of the possible changes in climatic niches.

The present study examines the risk of increasing damage caused by selected pests due to shifting climate conditions. The primary result of the study shows the shift of developmental limitations of pest species and subsequent widening of their areas of occurrence and shifts to higher altitudes coupled with producing 
more generations. This result is in agreement with other studies suggesting the increasing geographical ranges of cold-limited species. In addition, the present study shows that the risk of increased pest damage is greater at higher altitudes.

Acknowledgements. This study was supported by research plan No. MSM6215648905, 'Biological and technological aspects of sustainability of controlled ecosystems and their adaptability to climate change,' by the 6th FP EU project ADAGIO (Adaptation of Agriculture in European Regions at Environmental Risk under Climate Change) SSPE-CT-2006044210, by the 6th FP EU research project CECILIA (no GOCE 037005), by KONTAKT OC187 (linked to COST 734), and by the project of Czech Science Foundation 521/08/1682 ('Effect of climate variability and meteorological extremes on the production of selected crops between 1801 and 2007'). The climate change scenarios were prepared as part of the project IAA300420806 ('Probabilistic Climate Scenarios for the Czech Republic') sponsored by the Grant Agency of Academy of Sciences of the Czech Republic.

\section{LITERATURE CITED}

Anderson TE, Kennedy GG, Stinner RE (1982) Temperaturedependent models of ECB (Lepidoptera: Pyralidae) development in North Carolina. Environ Entomol 11:1145-1150

Araujo MB, Luoto M (2007) The importance of biotic interactions for modelling species distributions under climate change. Glob Ecol Biogeogr 16:743-753

Archer SR (1994) Regulation of ecosystem structure and function: climatic versus non-climatic factors. In: Griffiths JF (ed) Handbook of agricultural meteorology. Oxford University Press, Oxford, 245-255

Baker RHA, Sansford CE, Jarvis CH, Cannon RJC, Macleod A, Walters KFA (2000) The role of climatic mapping in predicting the potential geographical distribution of non-indigenous pests under current and future climates. Climates 82: $57-71$

Bale JS, Masters GJ, Hodkinson ID, Awmack C and others (2002) Herbivory in global climate change research: direct effects of rising temperature on insect herbivores. Glob Change Biol 8:1-16

Bell NL, Willoughby BE (2003) A review of the role of predatory mites in the biological control of Lucerne flea, Sminthurus viridis (L.) (Collembola: Sminthuridae) and their potential use in New Zealand. New Zeal J Agri Res 46:141-146

Cannon RJC (1998) The implications of predicted climate change for insect pests in the UK, with emphasis on nonindigenous species. Glob Change Biol 4:785-796

Downing TE, Harrison PA, Butterfield RE, Lonsdale KG (eds) (2000) Climate change, climatic variability and agriculture in Europe. An integrated assessment. Research Report No. 21, Contract No. ENV4-CT95-0154. Commission of the European Union, Brussels

Dubrovský M, Žalud Z, Štastná M (2000) Sensitivity of CERES-Maize yields to statistical structure of daily weather series. Clim Change 46:447-472

Dubrovský M, Buchtele J, Žalud Z (2004) High-frequency and low-frequency variability in stochastic daily weather generator and its effect on agricultural and hydrologic modelling. Clim Change 63:145-179

Dubrovsky M, Nemesova I, Kalvova J (2005) Uncertainties in climate change scenarios for the Czech Republic. Clim Res 29:139-156

EPPO (European and Mediterranean Plant Protection Organization) Plant Quarantine Data Retrieval System, PQR, version 4.6. www.eppo.org/DATABASES/pqr/pqr.htm, accessed 14 Oct 2009

Gaston KJ (2003) The structure and dynamics of geographical ranges. Oxford University Press, Oxford

Gaston KJ, Williams PH (1996) Spatial patterns in taxonomic diversity. In: Gaston KJ (ed) Biodiversity. Blackwell Science, Oxford, 202-229

Hare JD (1990) Ecology and management of the Colorado potato beetle. Annu Rev Entomol 35:81-100

Hill JK, Thomas CD, Huntley B (1999) Climate and habitat availability determine 20th century changes in a butterfly's range margin. Proc R Soc Ser B Biol Sci 266:1197-1206

Hill JK, Thomas CD, Fox R, Telfer MG, Willis SG, Asher J, Huntley B (2002) Responses of butterflies to twentieth century climate warming: implications for future ranges. Proc R Soc Ser B Biol Sci 269:2163-2171

Hoddle MS (2004) The potential adventive geographic range of glassy-winged sharpshooter, Homalodisca coagulata and the grape pathogen Xylella fastidiosa: implications for California and other grape growing regions of the world. Crop Prot 23:691-699

Hutchinson GE (1957) Concluding remarks. Cold Spring Harb Symp Quant Biol 22:415-427

Jarvis CH, Baker RHA (2001) Risk assessment for nonindigenous pests. I. Mapping the outputs of phenology models to assess the likelihood of establishment. Divers Distrib 7: 223-235

Kocmánková E, Trnka M, Žalud Z, Semerádová D, Dubrovský M, Muška F, Možný M (2008a) Comparison of two mapping methods of potential distribution of pests under present and changed climate. Plant Prot Sci 44:49-56

Kocmánková E, Trnka M, Semerádová D, Žalud Z and others (2008b) The change of the potential occurrence of Colorado potato beetle (Leptinotarsa decemlineata, Say 1824) in the Czech Republic till 2050. Acta Univ Agric Silvic Mendel Brun 2:87-94

> Kriticos DJ, Sutherst RW, Brown JR, Adkins SW, Maywald GF (2003) Climate change and the potential distribution of an invasive alien plant: Acacia nilotica ssp. indica in Australia. J Appl Ecol 40:111-124

> Lockett CJ, Palmer WA (2003) Rearing and release of Homichloda barkeri (Jacoby) (Coleoptera: Chrysomelidae: Alticinae) for the biological control of prickly acacia, Acacia nilotica ssp indica (Mimosaceae) in Australia. Aust J Entomol 42:287-293

Lyytinen A, Lindstrom L, Mappes J (2008) Genetic variation in growth and development time under two selection regimes in Leptinotarsa decemlineata. Entomol Exp Appl 127:157-167

Olesen JE (2008) Climate change as a driver for European agriculture. Conference on 'Europe's rural areas in action: facing the challenges of tomorrow,' October 16-17, 2008, Limassol, Cyprus

Olfert O, Weiss RM (2006) Impact of climate change on potential distributions and relative abundances of Oulema melanopus, Meligethes viridescens and Ceutorhyncus obstrictus in Canada. Agric Ecosyst Environ 113:295-301

> Parmesan C, Ryrholm N, Stefanescu C, Hill JK and others (1999) Poleward shifts in geographical ranges of butterfly species associated with regional warming. Nature 399: 579-583

> Parry ML, Rosenzweig C, Iglesias A, Livermore M, Fischer G (2004) Effects of climate change on global food production 
under SRES emissions and socio-economic scenarios. Glob Environ Change 14:53-67

Pethybridge SJN, Wilson ME (2003) Forecasting climate suitability of Australian hop-growing regions for establishment of hop powdery and downy mildews. Australas Plant Pathol 32:493-497

Pollard E, Yates TJ (1993) Monitoring butterflies for ecology and conservation. Chapman \& Hall, London

Pollard E, Moss D, Yates TJ (1995) Population trends of common British butterflies at monitored sites. J Appl Ecol 32: 9-16

Porter JH, Parry ML, Carter TR (1991) The potential effects of climatic change on agricultural insect pests. Agric For Meteorol 57:221-240

Rafoss T, Sæthre MG (2003) Spatial and temporal distribution of bioclimatic potential for the codling moth and the Colorado potato beetle in Norway: model predictions versus climate and field data from the 1990s. Agric For Entomol 5: $75-85$

Shreeve TG, Dennis RHL, Pullin AS (1996) Marginality: scale determined processes and the conservation of the British butterfly fauna. Biodivers Conserv 5:1131-1141

Sutherst RW (2000a) Climate change and invasive speciesa conceptual framework. In Mooney HA, Hobbs RJ (eds) Invasive species in a changing world. Island Press, Washington DC, 211-240

Sutherst RW (2000b) Climate variability, seasonal forecasting and invertebrate pests - the need for a synoptic view. In: Hammer GL, Nicholls N, Mitchell C (eds) Applications of seasonal climate forecasting in agricultural and natural ecosystems. The Australian Experience. Kluwer, Dordrecht, 381-397

Sutherst RW (2003) Prediction of species geographical ranges. J Biogeogr 30:805-816

Sutherst RW, Maywald GF (1985) A computerised system for matching climates in ecology. Agric Ecosyst Environ 13: 281-299

Submitted: April 8, 2010; Accepted: July 6, 2010
Sutherst RW, Maywald GF, Russell BL (2000) Estimating vulnerability under global change: modular modelling of pests. Agric Ecosyst Environ 82:303-319

Sutherst RW, Maywald GF, Bottomley W, Bourne A (2001) CLIMEX v2 user's guide, CSIRO Entomol 13:281-299

Thomson LJ, Macfadyen S, Hoffmann AA (2010) Predicting the effects of climate change on natural enemies of agricultural pests. Biol Control 52:296-306

Tobin PC, Nagarkatti S, Loeb G, Saunders C (2008) Historical and projected interactions between climate change and insect voltinism in a multivoltine species. Glob Change Biol 14:951-957

Tran JK, Ylioja T, Billings RF, Regniere J, Ayres MP (2007) Impacts of minimum winter temperatures on the population dynamics of Dendroctonus frontalis. Ecol Appl 17: 882-899

Trnka M, Mužka F, Semerádová D, Dubrovský M, Kocmánková E, Žalud Z. (2007) European corn borer life stage model: regional estimates of pest development and spatial distribution under present and expected climate. Ecol Model 207:61-84

van Asche M, van Tienderen P, Holleman LJM, Visser ME (2007) Predicting adaptation of phenology in response to climate change, an insect herbivore example. Global Change Biol 13:1596-1604

Wilf P, Labandeira CC (1999) Response of plant-insect associations to Paleocene-Eocene warming. Science 284: 2153-2156

Yamamura K, Yokozawa M (2002) Prediction of a geographical shift in the prevalence of rice stripe virus disease transmitted by the small brown planthopper, Laodelphax striatellus (Fallen) (Hemiptera: Delphacidae), under global warming. App Entomol Zool 37:181-190

Zalucki MP, Furlong MJ (2005) Forecasting Helicoverpa populations in Australia: a comparison of regression based models and a bio-climatic based modelling approach. Insect Sci 12:45-56

Proofs received from author(s): September 21, 2010 